\title{
Prevalence, Location and Morphology of Maxillary Sinus Septa in an United States Dental School Population
}

\section{Yueh Ju Hsiao"*, Jie Yang ${ }^{2}$, Randolph R Resnik ${ }^{3}$ and Jon B Suzuki ${ }^{4}$}

${ }^{1}$ Assistant Professor in the Department of Periodontology and Oral Implantology, Temple University Kornberg School of Dentistry, Philadelphia, Pennsylvania, USA

${ }^{2}$ Professor and Director of Oral and Maxillofacial Radiology, Temple University Kornberg School of Dentistry, Philadelphia, Pennsylvania, USA ${ }^{3}$ Clinical Professor, Department of Periodontology and Oral Implantology, Temple University Kornberg School of Dentistry, Philadelphia, Pennsylvania, USA

${ }^{4}$ Professor, Department of Periodontology and Oral Implantology, Temple University Kornberg School of Dentistry, Philadelphia, Pennsylvania, USA

*Corresponding Author: Yueh Ju Hsiao, Assistant Professor in the Department of Periodontology and Oral Implantology, Temple University Kornberg School of Dentistry, Philadelphia, Pennsylvania, USA

Received: October 25, 2019; Published: November 22, 2019

DOI: $10.31080 /$ ASDS.2019.03.0710

\begin{abstract}
Objectives: The presence of sinus septa may cause complications in sinus augmentation surgery for dental implant therapy. Purpose of this study is to determine prevalence, location and morphology of maxillary sinus septa.

Methods: Eight hundred and twenty-one cone beam computed tomography scans were retrospectively evaluated for the prevalence, location and morphology of sinus septa. Age, gender, ethnicity, and dentition status were also evaluated to determine potential relationship of the presence of septa.

Results: Sinus septa were present in $44.56 \%$ scans and $35.7 \%$ sinuses. $26.76 \%$ of subjects presented sinus septa on both sinuses. $17.79 \%$ of subjects had one or multiple septa on either side. Septa height has a mean of $5.26 \mathrm{~mm}$ (range of 1.2 to $22.30 \mathrm{~mm}$ ). The most common sinus septa location is the second premolar region. Orientation of septa was $67.8 \%$ vertical, $31.68 \%$ transverse, and $0.51 \%$ horizontal. Complete septa were found in only $0.01 \%$ of the subjects. The age and gender factors are not statistically significant. Conclusions: Incidence of septa was found in $44.56 \%$ scans. Most common orientation of septa is vertical following by transverse. Most septa are incomplete and located in second premolar region. Different ethnic populations may present with different prevalence of sinus septa. Septa should be identified and surgical technique may need to be modified to minimize complications during sinus augmentation procedures.
\end{abstract}

Keywords: Cone Beam Computed Tomography; Maxillary Sinus Augmentation

\section{Introduction}

Maxillary sinus septa were first analyzed regarding their prevalence and characteristics by Arthur S. Underwood, and thus also referred to as Underwood's septa [1]. Underwood1 defined septa as a sickle-shaped reaching up the inner to outer wall. Septa is an irregular development (irregular as to period as well as shape, size and position) and can be categorized into primary and secondary septa. Primary septa originate during maxillary development, root formation, and tooth eruption [2]. Secondary septa are acquired structures resulting from pneumatization of maxillary sinus after tooth loss [2-5].

Septa are frequently divided the sinus into 3 basins, a small anterior one over the premolar region, a large median one 
descending between roots of the first and second molars and a small posterior one corresponding to the third molar region and extending backwards and upwards slightly beyond the third molar roots. The sections of floor of sinus often marked off by ridges, rising sometimes to distinct septa, correspond to 3 defined periods of tooth activity, which are separated from each other by intervals of tooth eruptions.

Sinus septa have gained practical relevance for periodontists, oral and maxillofacial surgeons as well as otolaryngologists [68]. Identification of maxillary sinus septa has gained increasing importance for sinus augmentation and dental implant procedures because septa presence may increase the risk of Schneiderian membrane perforation9. The perforation of the Schneiderian membrane may be associated with the development of maxillary sinusitis [10-15].

With advanced of diagnostic imaging with cone beam computerized tomography ( $\mathrm{CBCT}$ ), the presence of sinus septa can be determined prior to sinus augmentation and dental implant procedures. The study aims to determine the prevalence, location and morphology of maxillary sinus septa in dental school patients. The study also aims to determine if age, gender, ethnicity, and dentition status have a relationship on the prevalence of maxillary sinus septa.

\section{Materials and Methods}

The study was based on a retrospective evaluation of CBCT scans taken from 2009 to July 31, 2013. The study received Temple University Office for Human Subjects Protections Institutional Review Board approval (no 20906). Eight hundred and twenty-one (821) scans were screened initially. CT images with inadequate information (e.g. absent of maxillary sinus, the field of images did not extend including orbital floor and ostium, unclear images, multiple data of same subject) were excluded. A total of 680 scans of which subject factors of gender, age, ethnicity, and dentition status were finally included in the study. The CT scans were performed using i-CAT machine (Imaging Science International, Inc. Hatfield, PA, USA) with flat panel image detector. Images were taken at 120 kvp, $5 \mathrm{~mA}$, and a voxel size of $0.3 \mathrm{~mm}$, with an exposure time of 8.9 seconds. Fourteen (14) bits gray scales and 8.9 second scan times. The number of slices in one CBCT volume is 327 .

Obtained CBCT images were viewed using i-CAT vision viewing software giving a panoramic reconstruction view module and the MPR screen module, i.e. axial, sagittal and coronal slides. All images were assessed under standardized conditions at the same examination workplace (Window XP with Microsoft Offices Software). All scans were analyzed twice by one observer (periodontal resident) and questionable findings were discussed with a boarded oral and maxillofacial radiologist (J.Y.) and $10 \%$ of the data were calibrated with a boarded periodontists (J.B.S.).

The mean age of patients at the time of scan was 48.53 years (range 8 - 90 years). There were 360 females and 320 males. There were 408 Caucasians, 160 African Americans, 61 Asians, and 51 Hispanics. The subjects were also categorized based on age into 9 groups. < 13 years, 13 - 19 years, 20 - 29 years, 30 - 39 years, 40 - 49 years, 50 - 59 years, 60 - 69 years, $70-79$ years and $80-90$ years. Group 0 to 5 were combined to group age $<60$ and group 6 to 8 were combined to group age $>60$ for the convenient of statistical analysis. There were 413 aged $<60$ years and 267 aged $>60$ years.

The maxillary sinuses septa findings were categorized to no sinus septa presence, presence of one septa, and presence of multiple (> 1) septa in either right or left maxillary sinus. Orientation of sinus septa is categorized into transverse (mesial to lateral wall), vertical (inferior to superior wall), and horizontal (anterior to posterior wall) (Figure 1). Location of the septa is also determined by the location of the existing tooth except in the partial or complete edentulism patient, the location is determined into anterior, middle and posterior portion of the maxillary sinus.

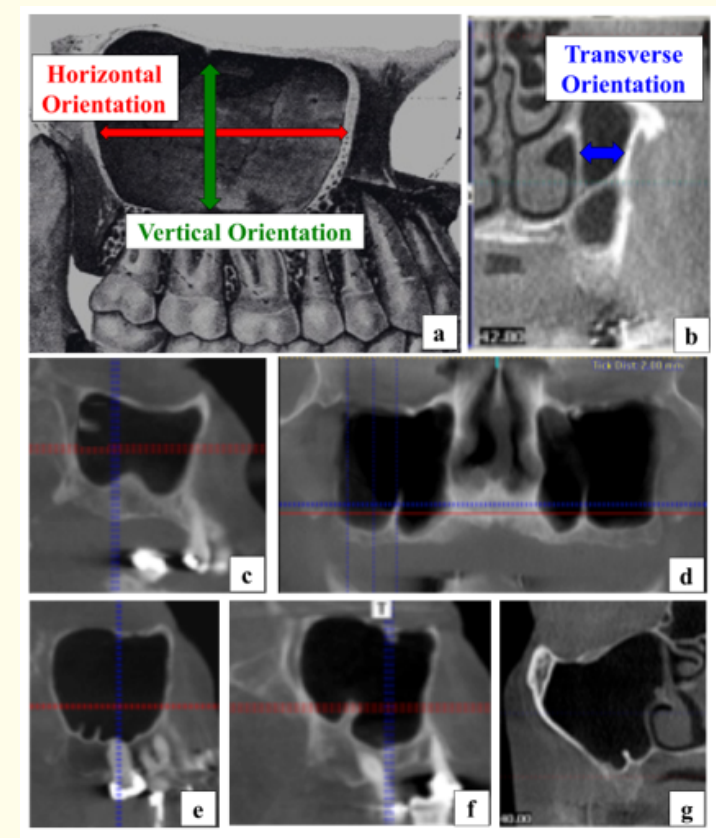

Figure 1: Direction and orientation of sinus septa. (a): Sagittal view of maxillary sinus cavity. Vertical orientation was anterior to posterior sinus wall direction. Horizontal orientation was inferior to superior sinus wall direction. (b) Transverse CBCT view. Transverse orientation is from lateral to medial wall. (c) Example of horizontal orientation of sinus septa. (d) Vertical orientation of sinus septa on both sinuses. (e) Presence of multiple sinus septa.

(f, g) Single sinus septa present. 
Dentition status of each side of the sinus were categorized into complete dentition regardless presence of third molar (CD), complete edentulism (CE), partial edentulism (PE), partial edentulism with implants (PI), complete edentulism with implants (PI), and mixed dentition (MD).

Data were recorded using Microsoft Excel spreadsheet and R project (http://www.r-project.org) was used for statistical analysis of the results. Multinomial logistic regression was then applied to right pathology and left pathology data separately to determine if gender, ethnicity or age has any relationship on pathology incidence. The septa occurrence is handled as a "Yes", "No" dichotomous variable on individual patient. The raw data are polled together as a Yes; if a patient has a single septum, multiple septa, either one side, or both sides. Dentition status is not evaluated due to the complexity of classification. The age of the patients is categorized into two groups: $<60$ years and $\geq 60$ years.

A chi-square test was conducted on each independent variable to detect the association between the selected variable and septa occurrence. The validity of the logistic regression model was evaluated by lack of fit test and likelihood test. 95\% confidence intervals of pathology incidence rates were calculated with normal approximation under binomial distribution assumption.

\section{Results}

Of the 680 CBCT scans, which were reviewed, 303 subjects have either one or multiple sinus septa presence in one or both maxillary sinuses. This translated to a prevalence of maxillary sinus septa of $44.56 \%$ in the population studied, with the remaining $55.44 \%$ not significant for any finding of maxillary sinus septa. Out of the 303 subjects, 182 subjects (60.1\%) with sinus septa in both sinuses, and 121 subjects (39.9\%) with sinus septa in either right or left side of maxillary sinus. Therefore, out of 1360 sinuses, 485 sinuses (35.67\%) presented with either one or multiple septa (Figure 2).

Septa height has a mean of $5.26 \mathrm{~mm}$ (range of 1.2 to 22.30 $\mathrm{mm}$ ). 187 septa are presented in vertical orientation, 400 septa in transverse orientation, and 3 septa in horizontal orientation. This translated to $67.8 \%$ in vertical orientation, $31.68 \%$ in transverse, and $0.51 \%$ in horizontal. There are 6 complete septa $(0.01 \%)$ and 590 incomplete septa (99.99\%).

Location of the septa were categorized into teeth location, first premolar, between first and second premolar, second premolar, between second premolar and first molar, first molar, between first and second molar, second molar, third molar and tuberosity area. There are few septa, unable to determine exact tooth location due

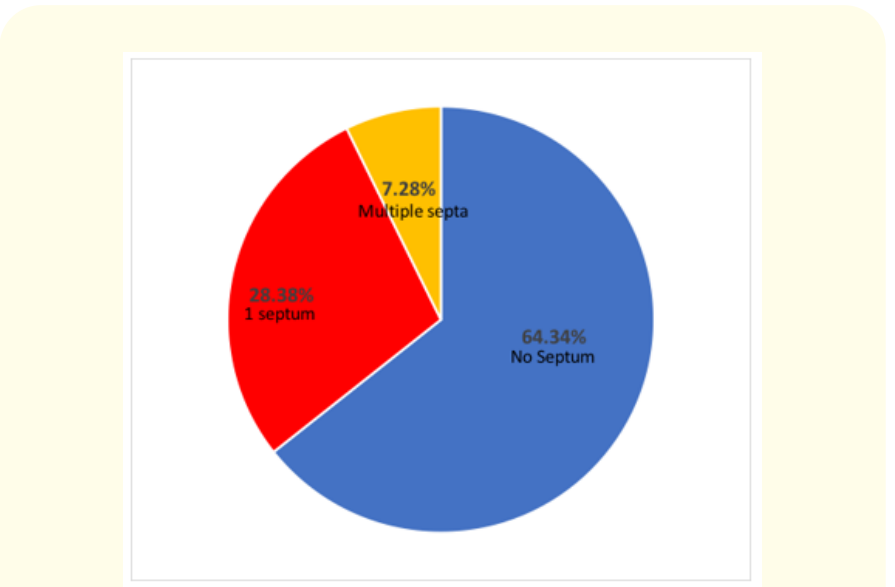

Figure 2: Percent of sinuses exhibiting septa on either side, bilaterally or no septum. $64.34 \%$ sinuses do not have septum. $28.38 \%$ sinuses present with 1 septum. $7.28 \%$ of sinuses present with multiple septa.

to edentulism. The most common location is the second premolar region (162 sinuses). Location is also categorized into anterior (first and second premolar), middle (first and second molar), and posterior (third molar and retromolar pad) region. Septa were located in anterior, middle, and posterior regions in 43.4\%, 42.03\% and $14.6 \%$ respectively (Table 1 ).

When categorizing in terms of gender of 360 female and 320 male studied, 153 females and 150 males presented with evidence of sinus septa. This translated to $22.50 \%$ of females and $22.06 \%$ of male with evidence of sinus septa (Figure 3). There is no statistical significant difference $(p=0.252)$ (Table 2$)$. In both gender, most common prevalence is bilateral single septum present in both sinuses, following by 1 septum on one side.

When categorizing the results in terms of ethnicity, the prevalence of sinus septa was $27.79 \%, 4.12 \%, 3.97 \%$, and $8.68 \%$ respectively for the groups Caucasians, African Americans, Asians and Hispanics (Figure 3). There was no statistically significant difference as a group ( $p=0.65$ in lack of fit test) (Table 2). However, in the regression analysis, Wald tests imply that the prevalence of septa in Caucasian and Hispanic group are significantly different from African American group ( $p=0.042$ and $p=0.044$ ). In the fitted model, the odds of having septa for Asian patients is 1.452 times higher than African American, and the odds of having septa in Caucasian is 1.477 times higher than African Americans, and the odds of having septa in Hispanic patients is 1.925 times higher than African American patients. 
Prevalence, Location and Morphology of Maxillary Sinus Septa in an United States Dental School Population

\begin{tabular}{|c|c|c|c|c|c|c|c|c|c|}
\hline \multirow[t]{2}{*}{ Dentition Status } & PM1 & PM1-PM2 & PM2 & PM2-M1 & M1 & M1-M2 & M2 & \multirow{2}{*}{$\begin{array}{c}\text { M3/ Tuberosity } \\
\text { Posterior }\end{array}$} & \multirow{2}{*}{$\begin{array}{c}\text { Unable to determine } \\
\text { exact tooth location } \\
\begin{array}{c}\text { Anterior/Middle/Pos- } \\
\text { terior }\end{array} \\
\end{array}$} \\
\hline & \multicolumn{4}{|c|}{ Anterior (PM1-PM2) } & \multicolumn{3}{|c|}{ Middle (M1-M2) } & & \\
\hline Complete dentition & 30 & 9 & 75 & 3 & 32 & 0 & 33 & 30 & $0 / 1 / 1$ \\
\hline Partial edentulism & 31 & 3 & 68 & 5 & 54 & 2 & 52 & 26 & $1 / 12 / 12$ \\
\hline $\begin{array}{l}\text { Complete edentulism/ } \\
\text { Implant }\end{array}$ & 0 & 0 & 1 & 0 & 0 & 0 & 0 & 0 & $0 / 3 / 0$ \\
\hline $\begin{array}{l}\text { Partial Edentulism/ } \\
\text { Implant }\end{array}$ & 3 & 0 & 9 & 0 & 9 & 0 & 9 & 1 & 0 \\
\hline Mixed Dentition & 1 & 0 & 3 & 0 & 0 & 0 & 0 & 2 & 0 \\
\hline
\end{tabular}

Table 1: Summary of the sinus septa location.

Premolar (PM), M (Molar)

\begin{tabular}{|l|c|c|c|}
\hline Model & Multinomial logistic regression analysis & Lack of Fit Analysis & Likelihood Test \\
\hline Age & $\mathrm{p}=0.755$ & $\mathrm{p}=0.3514$ & $\mathrm{P}=0.7554$ \\
\hline Gender & $\mathrm{p}=0.252$ & $\mathrm{p}=0.4361$ & $\mathrm{p}=0.252$ \\
\hline Ethnicity & $\begin{array}{c}\text { Asian } \mathrm{p}=0.221 \\
\text { Caucasian } \mathrm{p}=0.042^{*} \\
\text { Hispanic } \mathrm{p}=0.044^{*}\end{array}$ & $\mathrm{p}=0.65$ & $\mathrm{p}=0.1176$ \\
& $\begin{array}{r}\text { (1) } \\
\text { where the baseline is African American }\end{array}$ & & \\
\hline
\end{tabular}

Table 2: Regression analysis, lack of fit analysis, and likelihood test.

(*Indicate statistically significant variables related to dependent outcome variable)
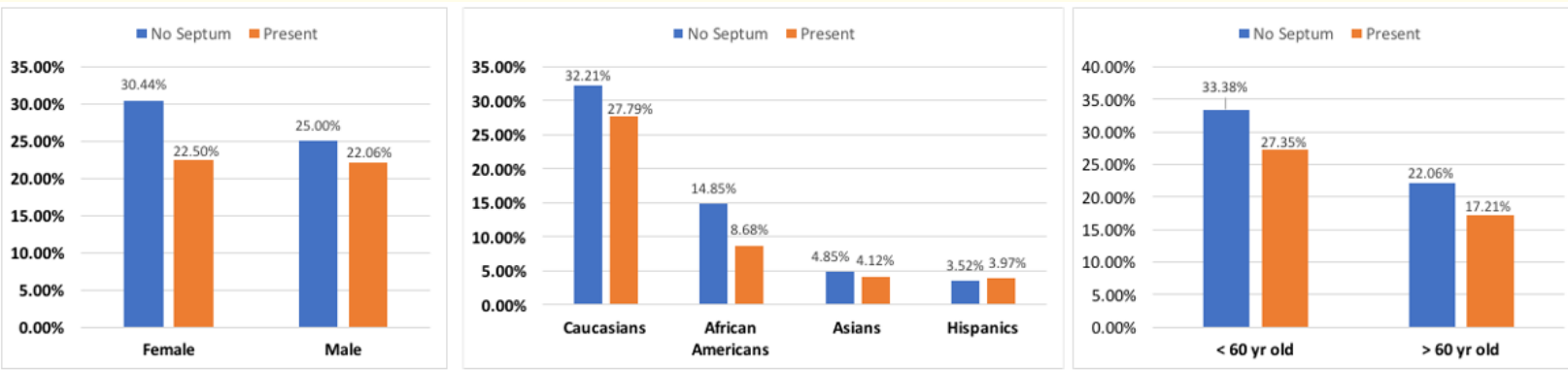

Figure 3: Maxillary sinus septa findings by gender, ethnicity and age. $30.44 \%$ of female and $25.00 \%$ of male do not have sinus septum. $22.50 \%$ female and $22.06 \%$ male present with one septum or multiple septa in maxillary sinus. $32.21 \%$ Caucasians, $14.85 \%$ African Americans, 4.85\% Asians, and 3.52\% Hispanics do not have sinus septum. 27.79\% Caucasians, 8.68\%, African Americans 4.12\% Asians, and 3.97\% Hispanics present with one septum or multiple septa. 33.38\% present no septum and $27.35 \%$ with one or multiple septa in subjects $<60$ year old. $22.06 \%$ present no septum and $17.21 \%$ with one or multiple septa in subjects $>60$ year old. 
When categorizing the results in terms of age, 186 subjects < 60 years and 117 subjects $>60$ years presented with sinus septa, which translated to $17.21 \%$ and $27.35 \%$ (Fig. 3). There is no statistical significant difference $(p=0.755)$ (Table 2).

\section{Discussion}

Previous studies on various population subsets have reported the prevalence of sinus septa in the range of 18.3 to $66.7 \%$. The prevalence of sinus septa is in range (44.56\%) with other studies that have previously addressed the topic with cadaver studies, and direct clinical measurements, CBCT studies, and panoramic radiographs.

Underwood 1910 [1]. described the first 45 skulls he examined, 30 contained more or less well-developed septa between a quarter and half an inch in height.

Ulm 1995 [16]. examined 41 edentulous maxilla, 31.7\% with at least 1 septum were present. $26.8 \%$ showed one septum, and 4.9\% exhibited 2 septa. Most septa were located between second premolar and first molar. The mean height of the septa was $7.9 \mathrm{~mm}$ with the highest septum height of $17 \mathrm{~mm}$. Most septa presented in frontal (transverse) orientation.

Krennmair 1999 [12,13]. studied using different examination methods, cadaver, direct clinical measurements, and CBCT. 27.8\% (17 of 61) patients who underwent sinus augmentation showed false diagnosis (in $21.3 \%$ cases) using panoramic radiographs. In cadaver (anatomic) study, 31.7\% (13 of 41) maxilla had 15 antral septa (36.6\%) on the sinus floor, $26.8 \%$ had one septum and $4.8 \%$ had 2 septa. 11 septa in anterior portion, 2 in the middle and 1 in the posterior. With CBCT analysis, 28.5\% of 42 complete edentulism and 50 partial edentulous). Analysis of the completely or partially dentate maxilla $(n=50)$ showed fewer septa. $70 \%$ of the septa were located in the anterior maxillary portion. Mean height of septa is $8.6+3.5 \mathrm{~mm}$ in panoramic radiograph, $7.9+4.2 \mathrm{~mm}$ in anatomically measured, $7.7+3.8$ in CBCT complete edentulism, $12.2+7.5$ in partial edentulism/complete dentate.

Velásquez-Plata 2002 evaluated 312 sinuses of 106 women and 50 me with age ranging between 24 to 86 years [17]. 24\% of septa were found in sinuses and $32.7 \%$ were found in patients. $33.3 \%$ of septa were present in completely edentulous patients and $66.7 \%$ of the septa were found in partially edentulous patients. In term of location, $24 \%$ septa were located in anterior region, $41.0 \%$ were in the middle and $35 \%$ were in the posterior region [17].
Shibli 2007 [18] evaluated 1024 panoramic radiographs. $21.58 \%$ presented with maxillary septa. 8.4\% showed septa presented bilaterally. No statistical significant regarding of age and gender.

Ella 2008 [19] studied 150 sinuses from 40 male cadavers, and 35 randomized patients by anatomical dissection and computed tomography. $61 \%$ showed no septa present or had septa $<4 \mathrm{~mm}$. $39 \%$ showed bony septa with 7 incomplete, 1 complete and 20 symmetrical septa.

Naitoh 2009 [20] evaluated 15 dry skulls with a CBCT unit. 12 septa $>2 \mathrm{~mm}$ was observed in 11 maxillary sinuses. $42 \%$ of septa were antero-posteriorly aligned.

Rosano 2010 [2] studied 60 sinuses from 30 human cadavers with age 59 to 90 years. Septa definition is $>3 \mathrm{~mm}$ in this study. $33.3 \%$ presented with incomplete septa. All located in the anteriorlateral wall and were either sagittal or transverse. 30\% in anterior region, $40 \%$ in middle, and $30 \%$ in posterior region. Mean septa height of $8.72 \mathrm{~mm}$ with range $3.7-18.4 \mathrm{~mm}$.

In other direct measurements studies, Jensen and Greer 1992 [21]. showed $56.7 \%$ of 26 patients presented with sinus septa. Zijderveld 2008 [22]. showed $48 \%$ of 100 patients presented with sinus septa during maxillary sinus floor elevation.

In CBCT studies, Lugmayr 1996 [23] showed 13.7\% in 200 patients presented with sinus septa. Kasabah 2002 [24] showed prevalence of $35.9 \%$ in 68 patients. Velásquez-Palata 2002 [17] studied 156 patients (106 women and 50 men with age ranging from 24 to 86 years). 75 septa were found in 312 maxillary sinuses (24\%) which corresponded to $32.7 \%$ of patients. Completely edentulous patients presented with $33.3 \%$ of total septa and $66.7 \%$ of septa were identified in partially edentulous patients. $24 \%$ septa were located in anterior region, $41 \%$ in the middle and $35 \%$ were in posterior region. Height of septa ranges from 0 to $15.7 \mathrm{~mm}$ (mean $3.54 \mathrm{~mm}$ ) in posterior (lateral) region, middle area ranged from 0 to $17.3 \mathrm{~mm}$ (mean $3.14 \mathrm{~mm}$ ), and anterior (medial) region ranged from 0 to $20.6 \mathrm{~mm}$ (mean $7.59 \mathrm{~mm}$ ).

Kim 2006 [25] studied 100 patients (41 women and 59 men, with mean age of 50 range from 19 and 87 years). The prevalence of one or more septa per sinus was found to be $26.5 \%, 31.76 \% 22.61 \%$ in overall study population, the edentulous, and non-atrophic/ dentate maxillary segments. $25.4 \%$ were located in anterior region, 
$50.8 \%$ in the middle region, and $23.7 \%$ in the posterior region. The heights of septa varied among different areas. Mean heights were $1.63,3.55$, and 5.46 in lateral, middle and medial areas respectively. This study did not discuss the orientation of the septa.

González-Santana 2007 [26] studied 30 patients (60 sinuses). $20 \%$ of sinuses and $25 \%$ of patients had septa. The septa were located as follows: 2 anterior, 11 middle, and 4 posterior. Heights were between 2.5 and $6 \mathrm{~mm}$ long.

Selcuk 2008 [27] studied 330 paranasal sinuses of patients presenting with sinonasal complaints to ear nose throat physicians. $20.3 \%$ anteriorly and $2.5 \%$ posterior localized maxillary sinus bony septa. The position was frequently vertical at anterior, and horizontal at posterior. This study found significant correlation between the anteriorly localized maxillary sinus septa and Infraorbital fissure enlargement. The study mention the presence of mucosal pathology was significant in patients with maxillary sinus septa.

Lee 2010 [28] study exclude cases presenting any sinus pathological changes. 236 maxillary sinuses in 204 patients were analyzed. The mean age of the patients was 50.9 years. $20.9 \%$ of 204 patients presented with pathologic findings. Sinus septa were present in $24.6 \%$ of 236 maxillary sinuses and $27 \%$ of patients. Septa were found in $27.3 \%$ in anterior, $50 \%$ in the middle and $22.7 \%$ in the posterior region.

Maestre-Ferrin 2011 [29] studied 30 patients (17 women and 13 men, with a mean age of 50.9 years). In 60 maxillary sinuses, panoramic radiographs showed $53.3 \%$ prevalence and CT showed $66.7 \%$. Most septa (60\%) located in the middle region of the maxillary sinuses, $22.5 \%$ in the posterior region and $17.5 \%$ in the anterior region. The mean height of the septa was $4.78 \mathrm{~mm}$.

Neugebauer 2010 [30] evaluated 1029 scans. Septa were found in $47 \%$ of patients, and $33.2 \%$ sinuses. There was no statistical difference in prevalence with respect to age, sex or side. Most patients with septa showed one septum in one sinus $(24.6 \%)$; $13.7 \%$ showed 1 septum in each sinus. Other combination up to 3 septa were found in $8.7 \%$ of patients. Septa were most commonly located in the first molar region, followed by second molar region and the canine region. The orientation of septa is $25.3 \%$ in sagittal and $74.7 \%$ in transverse.
Park 2011 [31] studied 200 patients. 111 septa presented in 400 maxillary sinuses $(27.7 \%)$, which corresponded to $37 \%$ of patients. $22.5 \%$ were located in the anterior, $45.9 \%$ in the middle and $31.5 \%$ in the posterior region. The directional orientation analyses showed that 106 septa were buccopalatal, 4 were sagittal and 1 was transverse type. Mean heights were 7.78 and 7.89 in the right and left sinuses respectively.

Shen 2012 [32]. studied 423 Taiwanese patients with 216 women and 207 men, mean age 53.65 years). 30\% subjects had sinus septa and $20.45 \%$ of sinuses. $22.93 \%$ presented with multiple septa. Most frequent location is in the region of first and second molar. The prevalence was not related to tooth loss (edentulous, partially edentulous or dentate maxillary segments. Logistic regression analysis showed that men were significantly more likely to have septa than were women.

Pommer 2012 [6] systemic review and meta-analysis of prevalence, location and morphology of maxillary sinus septa. He concluded that septa were present in $28.4 \%$ of 8923 sinuses investigated. Prevalence was significantly higher in atrophic sinuses compared with dentate maxillae. Septa were located in premolar, molar and retromolar regions in $24.4 \%, 54.6 \%$, and $21 \%$ respectively. Orientation of septa was transverse in $87.6 \%$, sagittal in $11.1 \%$ and horizontal in $1.3 \%$. Septa height measured $7.5 \mathrm{~mm}$ on average. Complete septa were found in only $0.3 \%$. 04.2\% presented with multiple septa in one sinus and $17.2 \%$ in bilateral septa. Septa diagnosis using panoramic radiographs yielded incorrect results in $29 \%$ of cases.

Li 2013 [33] studied 424 patients from the Jiangsu region in China using CBCT. $44.81 \%$ subjects had sinus septa, $21.23 \%$ had multiple sinus septa, and $20.52 \%$ had bilateral septa. The prevalence was not related to age, gender, or the presence or absence of teeth. Septa were most commonly located in the middle of the maxillary sinus. Mean height of the septa was (5.90 \pm 3.65$)$ $\mathrm{mm}$ in the right sinus, and $(5.54 \pm 2.87) \mathrm{mm}$ in the left sinus. Mean length of septa was $(8.15 \pm 2.40) \mathrm{mm}$ in the right sinus and $(7.88 \pm$ 2.73) $\mathrm{mm}$ in the left sinus.

Orhan 2013 [34] studied 272 patients which included 242 adults and 30 children. $58 \%$ of the subjects had septa, which corresponded to $3.2 \%$ of completely edentulous (CE), $53.9 \%$ septa of edentate and $3.8 \%$ septa of the mixed dentition. Septa were 
most commonly located in the middle region of the maxillary sinus (69.1\%). Septa was found to be higher in partially edentulous patients than dentate and CE patients. There were no statistically significant differences in terms of gender or age.

Nunes 2013 [35] evaluated 122 CBCT scans of 252 edentulous sites. One septum was present in 67 edentulous sites. septum was present in 67 edentulous sites (26.59\%). Dobele 2013 [36] evaluated CBCT scans of 34 patients. Septa was found in $20.6 \%$ of subjects.

Jang 2014 [37] evaluated CBCT of 200 maxillary sinus in 100 dentulous patients 20 to 40 years of age and 62 maxillary sinus in 51 edentulous patients 50 to 80 years of age. In dentulous patients, prevalence of sinus septa is $27 \%$ in dentulous and $25.8 \%$ in edentulous patients. $22.5 \%$ dentulous patients and $17.7 \%$ edentulous patients presented with 1 septum, $4.5 \%$ of dentulous patients and $8.1 \%$ of edentulous patients presented with multiple septa. In term of direction of sinus septa, most common is buccopalatal direction in both dentulous (84.1\%) and edentulous (77.3\%) patients followed by transverse direction in dentulous (15.9\%) and edentulous (18.2\%) patients. Sagittal is the least common orientation with $0 \%$ in dentulous patients and $4.5 \%$ in edentulous patients. In dentulous patients, $47.6 \%$ septa were found in anterior third region, $34.9 \%$ in middle third and $17.5 \%$ in posterior third. In edentulous patients, $40.9 \%$ were found in middle third, $31.8 \%$ in anterior third and $27.3 \%$ in posterior third region.

Rancitelli 2015 [38] studied the relationship between the prevalence of the septum and the thickness of the schneiderian membrane. Of the 228 maxillary sinuses studied, $38.1 \%$ had sinus septa. Mean height of primary and secondary septa was $5.5 \mathrm{~mm}$ and $3.4 \mathrm{~mm}$ respectively. Medium thickness of mucosa was 0.85 $\mathrm{mm}$. When measured closer to the septa, it was $1.8 \mathrm{~mm}$. This study concluded that presence of septa may result thickening of the schneiderian membrane.

Gandhi 2015 [39] studied 210 cadaveric heads in formalin. He concluded that septa were presents in $28.1 \%$ of the specimens, and $55.9 \%$ of the specimens were in the middle region of the maxillary sinus cavity. Septa were more common in edentulous than dentate jaws. This study did not evaluate the orientation of the sinus septa.
Malec 2015 [40] evaluated 216 computed tomography scan with subjects age range 23 to 62 . The prevalence of sinus septa was 106 out of 216 scans (49\%). 163 septa was present in 432 sinuses and average height is $5.44 \mathrm{~mm}$. In most cases, one septum was more prevalence than multiple septa and found in $60 \%$ of scans. $69 \%$ of septa are found in middle region especially above second molar (66\%), 18\% in anterior region, and $13 \%$ in posterior region. The most frequent orientation was 59\% the coronal plane following by transversal and then sagittal. In term of gender, septa prevalence is $47 \%$ in men and $54 \%$ in female. The study also found highest rate of septa incidence in 50 to 59 age group.

Sánchez-Pérez 2016 [41] evaluated 160 CBCT scans comprises 71 men and 89 women). $26.3 \%$ of subjects presented with septa. $18.13 \%$ of subjects presented with septa unilaterally and $8.13 \%$ presented bilaterally. The study concluded there is possible association with sinus septa and schneidian membrane thickness.

Qian 2016 [42] analyzed CBCT scans of 506 patients (168 men and 338 women) with age range 12 to 79 years old. The prevalence of sinus septa was $48.2 \%$ in patients and $32.6 \%$ in sinuses. In terms of gender, prevalence rate were $45.2 \%$ for men and $49.7 \%$ for women. In term of number of septa, $84.9 \%$ presented with 1 septum, $13.9 \%$ with 2 septa and $2.2 \%$ with 3 septa. In term of location, $34.5 \%$ of septa in anterior region, $41.0 \%$ in middle region, and $24.1 \%$ in posterior region. In term of orientation, $93.8 \%$ were buccopalatally oriented, $4.9 \%$ were sagittally oriented and $1.3 \%$ were transversely oriented. In term of dentition status, $57.4 \%$ of septa were found in edentulous patients and 39.7\% in dentulous patients. There was significant occurrence of sinus septa in edentulous group compared to dentulous group.

Bornstein 2016 [43] studied 213 patients with 126 women and 86 men, mean age 53.8 years). $66.5 \%$ subjects and $56.5 \%$ of sinuses had sinus septa. $61.8 \%$ had coronal orientation, $7.6 \%$ had axial orientation, and $3.6 \%$ had sagittal orientation. Most frequent location is in the region of first and second molar.

Sakhdari 2016 [44] cross-sectional study of the prevalence, height, and location of maxillary sinus septa. He concluded that $44.8 \%$ of 946 sinuses investigated had at least 1 septa, $36.8 \%$ had 1 septa in their right sinus, $27.4 \%$ had 1 septa in their left, and $35.8 \%$ of the sinuses had septa in both sides. Septa were located in the middle of the sinus cavity in $35.1 \%$ of the subjects. The most 
common septa found was the mediolateral septa (59.2\%). In terms of the prevalence of the septa, there was no statistically significant differences in terms of gender or the right or left sinuses.

Toraman 2016 [45] compared panoramic radiographs and CBCT of 52 patients. Septa ere found in $23.1 \%$ on panoramics and $29.8 \%$ in CBCT images. $45.8 \%$ septa of panoramics and $64.5 \%$ septa of CBCT were observed in posterior maxilla.

Tadinada 2016 [46] evaluated 36 CBCT scans of 72 sinuses. Prevalence of sinus septa is $59.7 \%$ in sinuses. $27.7 \%$ showed a single septum, $23.6 \%$ showed 2 sinuses, and $6.9 \%$ showed 3 sinuses. $70.8 \%$ septa in transverse direction, $23.6 \%$ septa in sagittal direction and $6.9 \%$ septa in horizon direction. There was no significant difference in age and gender.

Keceli 2017 [47] evaluated 1160 CBCT scans. $1 / 3$ of the patients had at least one septum at the anterior of zygomatic process and around $16 \%$ of septa presented at the posterior of zygomatic process. Gender does not affect septa location and number.

Lozano-Carrascal 2017 [48] evaluated 300 CBCT scans. OF 284 scans, $20.56 \%$ septa in bucco-palatal oriented with a mean height of $13.11 \pm 3.82 \mathrm{~mm}$. $3.74 \%$ septa in sagittal direction and mean height of $12.24+1.25 \mathrm{~mm}$, and no septum in horizontal direction. In bucco-palatal direction, $40.91 \%$ found in second molar region, $22.73 \%$ in third molar region, $22.73 \%$ in first molar region, $13.64 \%$ in second premolar. In sagittal direction, $50 \%$ in second premolar region, $25 \%$ in first molar, $25 \%$ in third molar, and $0 \%$ in second molar position.

Dragan 2017 [5] evaluated 200 CBCT images of 100 dentate and 100 edentulous patients. In dentate patients, septa were located $55.4 \%$ in posterior region, $33.7 \%$ in middle region and $10.9 \%$ in anterior region. Spatial orientation of septum was $18.8 \%$ in transverse direction, $81.2 \%$ oblique. In edentulous patients, $53 \%$ of septa were oblique and $47 \%$ were transverse. There was no sagittal direction in either group. 98\% dentate patients and $96 \%$ of edentate patients presented with complete septa and $2 \%$ dentate patients and $4 \%$ edentate patients presented with incomplete septa.

Teleghani 2017 [49]. evaluated 300 CBCT images of Iranian subjects for the prevalence, location, and size of the sinus septa. He concluded $44 \%$ of the patients had septa. Location of the septa was equally found in the anterior, middle, and posterior part of the sinus cavity. The average height was $3.6 \pm 1.56 \mathrm{~mm}$

Talo 2017 [50] evaluated 500 CBCT images. 297 septa was found in 1000 maxillary sinuses (29.7\%) with mean height of 4.62 $+2.50 \mathrm{~mm}$. 29.4\% were identified in male patients, and $30.1 \%$ were found in female patients. The seta in atrophic, partial atrophic and non- atrophic maxillary crest type was $30.6 \%, 31.1 \%$ and $29.2 \%$ respectively. $5 \%$ had multiple septa. 247 sinuses had 1 septum and 25 sinuses had 2 septa. $26.4 \%$ septa were located in posterior region, follow by $24.5 \%$ in the middle region and $8.7 \%$ in anterior region. $26.1 \%$ septa were in mediolateral orientation, $3.7 \%$ in transverse orientation, and $0.2 \%$ in sagittal orientation. There is no statistically significance in term of gender and maxillary crest type.

Schriber 2017 [51] evaluated 100 CBCT scans composed of 50 dentate patients and 50 posterior maxilla edentulous patients. Prevalence of sinus septa was found $52 \%$ in dentate and $48 \%$ in edentulous posterior maxilla. There is no statistical significance between presence of septa and dentition status ( $\mathrm{p}=0.69) .56 .7 \%$ of septa was found on the floor of maxillary sinus, and the most common orientation was coronal $63.3 \%$. Majority of septa $(79.3 \%)$ were observed in the posterior maxilla in the region of second molars.

Khalighi 2017 [52] evaluated 222 patients' CBCT images from 20 to 81 years old. 265 out of 444 sinus septal patterns were found. 152 of $222(68.4 \%)$ patients showed one or more septa in one of the maxillary sinuses. A total of $42.1 \%$ of 152 patients had septa in either right or left maxillary sinus, and $57.9 \%$ had septa in both sinuses.

Irinakis 2017 [53] evaluated 79 CBCT images. 48.1\% septa were identified. $71.1 \%$ presented in buccal-lingual direction.

Genc 2018 [54] evaluated CBCT 87 scans of the maxilla. 43.7\% presented with sinus septa.

Hungerbühler 2019 [55] evaluated 301 CBCT scans. 188 septa were found in 602 sinuses. 38.9\% subjects presented with one or more septa. In term of septa direction, $53.2 \%$ of septa were coronally oriented, $24.5 \%$ were sagittally oriented, and $22.3 \%$ were transversely oriented. $37.2 \%$ septa were found in first and second molar region, $33.0 \%$ in third molar region, and $29.8 \%$ in canine premolar region. A significant association was found between present of septa and edentulism. 
Dedeoğlu 2019 [56] evaluated 258 maxillary sinus CBCT images of 140 patients. Septa prevalence was 26.4\%. 26.8\% was found in posterior dentate patients and $29.6 \%$ was found in posterior edentulous patients. In term of age group, $28.2 \%$ was found in elderly patients (over 50 years old) and $23.2 \%$ was found in young patient (under 50 years old). The study concluded there was no statistical significant difference between dentition status and age group.

Simsek Kaya 2019 [57] evaluated 228 maxillary sinuses in 114 patients. Septa were present in $42.1 \%$ of patients and $32.9 \%$ of sinuses. Single septum was found in $93.3 \%$ of sinuses and two septa was found in $6.7 \%$ of sinuses. All are incomplete septa. More than 3 septa were not found in any sinus. Significant difference was found in frequency of septa and patient's age or gender. No statistical significant found in term of patient's dentition status. $48.8 \%$ septa was found in middle region, followed by posterior region (26.3\%), and anterior region (25\%). Most frequent septa orientation is $60 \%$.

Zhang 2019 [58] evaluated 970 CBCT scans. Bony septum > 2 $\mathrm{mm}$ was found in $16.9 \%$ of sinuses and $26.0 \%$ of patients. $30.4 \%$ of septa were located in first and second premolar region, 50.7\% in the first and second molar region, and $18.9 \%$ in the posterior to second molar region. $92.1 \%$ sinuses had one septum, $7.6 \%$ had two septa and $0.3 \%$ had three septa present. The orientation of the septa was $91.0 \%$ transverse (buccopalatally) direction and 9.0\% in sagittal (mesiodistally) direction. There is no significance with septa prevalence and gender.

This study evaluated different parameters described from previous articles such as age, ethnicity, gender, septa orientation, and sinus location. None of the above article evaluated prevalence of sinus septa in term of ethnicity. Previous studies found sinus septa commonly located in the middle region corresponding to first and second molar region. This study found septa most commonly located in premolar regions (43.4\%) following by molar (42.03\%) and retromolar (14.6\%). In term of septa orientation, vertical is most common following by transverse and horizontal is rare [59], which is different from previous study indicate transverse was the most common direction. The study agree with complete septa was rare and single septum is more common finding than multiple septa.

\section{Conclusion}

Incidence of septa was found in $44.56 \%$ of the cone beam computed tomography (CBCT) scans. The age, gender, ethnicity factors are not statistically significant. Septa height has a mean of $5.26 \mathrm{~mm}$ (range of 1.2 to $22.30 \mathrm{~mm}$ ). Most common orientation of septa is vertical following by transverse. Horizontal orientation is rare. Most of the septa are incomplete. Only $0.01 \%$ presented with complete septa. Most common location is second premolar and anterior region, which is different from most study (molar and middle region). Single septum (28.38\%) is more common than multiple septa (7.28\%).

With 360 females and 320 males studied, $22.50 \%$ of females and $22.03 \%$ of male with evidence of septa. There was no statistically significant relationship observed between gender and prevalence of sinus septa.

The prevalence of sinus septa for the groups Caucasians, African Americans, Asians and Hispanics is as follows 27.79\%, $8.67 \%, 4.12 \%$, and $3.53 \%$. The ethnicity factor as a group is no statistical significant. However, Wald tests imply that prevalence of septa in Caucasian ( $p=0.042)$ and Hispanic group ( $p=0.044)$ are significantly different from African American group.

There were 413 patients younger than 60 year old and 267 subjects older than 60 . The prevalence of maxillary sinus septa was $27.35 \%$ and $17.21 \%$ for the groups $<60$ year old and $>60$ year old. There was no statistically significant difference.

Based on these findings, it is recommended that prior to sinus augmentation and dental implant procedures, CBCT scans should be carefully evaluated for the septa location and height since $44.56 \%$ have variations to prevent surgical complication such as perforations.

\section{Bibliography}

1. Underwood AS. "An inquiry into the anatomy the anatomy and pathology of the maxillary sinus". Journal of Anatomy and Physiology 44 (1910): 354-369.

2. Rosano G., et al. "Maxillary sinus septa: a cadaveric study". Journal of Oral and Maxillofacial Surgery 68.6 (2010):1360-1364.

3. Malec M., et al. "Maxillary sinus septa prevalence and morphology computed tomography based analysis". International Journal of Morphology 33.1 (2015): 144-148. 
4. Yang L., et al. "Quantitative evaluation of maxillary interradicular bone with cone-beam computed tomography for bicortical placement of orthodontic mini-implants". American Journal of Orthodontics and Dentofacial Orthopedics 147.6 (2015):725-737.

5. Dragan E., et al. "Three-dimensional evaluation of maxillary sinus septa for implant placement". Medical Science Monitor 23 (2017):1394-1400.

6. Pommer B., et al. "Prevalence, location and morphology of maxillary sinus septa: systematic review and meta-analysis". Journal of Clinical Periodontology 39.8 (2012): 769-773.

7. Testori T., et al. "Maxillary Sinus Surgery and Alternatives in Treatment". Quintessence Publishing (2009): 7-23.

8. Rysz M and Bakon L. "Maxillary sinus anatomy variation and nasal cavity width: structural computed tomography imaging". Folia Morphologica (Warsz) 68.4 (2009): 260-264.

9. Schwarz L., et al. "Risk factors of membrane perforation and postoperative complications in sinus floor elevation surgery: review of 407 augmentation procedures". Journal of Oral and Maxillofacial Surgery73.7 (2015):1275-1282.

10. Misch CE., et al. "38.Maxillary sinus anatomy, pathology, and graft surgery”. Contemporary Implant Dentistry (2008): 905974.

11. Betts NJ and Miloro M. "Modification of the sinus lift procedure for septa in the maxillary antrum". Journal of Oral and Maxillofacial Surgery 52.3 (1994): 332-333.

12. Krennmair G., et al. "Maxillary sinus septa: Incidence, morphology, and clinical implications". Journal of Cranio-Maxillofacial Surger 25.5 (1997): 261-265.

13. Krennmair G., et al. "The incidence, location, and height of maxillary sinus septa in the edentulous and dentate maxilla". Journal of Oral and Maxillofacial Surgery 57.6 (1999): 667671.

14. Van den Bergh JP., et al. "Anatomical aspects of sinus floor elevations". Clinical Oral Implants Research 11.3 (2000): 256-265.

15. Quiney RE., et al. "Maxillary sinusitis from dental osseointegrated implants". The Journal of Laryngology and Otology 104.4 (1990):333-334.

16. Ulm CW., et al. "Incidence and suggested surgical management of septa in sinus-lift procedures". The International Journal of Oral and Maxillofacial Implants 10.4 (1995):462-465.
17. Velásquez-Plata D., et al. "Maxillary sinus septa: A 3-dimensional computerized tomographic scan analysis". The International Journal of Oral and Maxillofacial Implants 17.6 (2002): 854-860.

18. Shibli JA., et al. "Prevalence of maxillary sinus septa in 1024 subjects with edentulous upper jaws: A retrospective study". Journal of Oral Implantology 33.5 (2007): 294-296.

19. Ella B., et al. "Septa within the sinus: Effect on elevation of the sinus floor". Br Journal of Oral and Maxillofacial Surgery 46.6 (2008): 464-467.

20. Naitoh M., et al. "Assessment of maxillary sinus septa using cone-beam computed tomography: etiological consideration". Clinical Implant Dentistry and Related Research 11 (2009): 5258.

21. Jensen OT and Greer R. "Immediate placement of osseouintegrating implants into the maxillary sinus augmented with mineralized cancellous allograft and Gore-tex: Second stage surgical and histologic findings. In: Laney WR, Tolman DE (eds). Tissue integration in Oral Orthopedic and Maxilofacial Reconstruction". Chicago: Quintessence (1992): 321-333.

22. Zijderveld SA., et al. "Anatomical and surgical findings and complications in 100 consecutive maxillary sinus floor elevation procedures". Journal of Oral and Maxillofacial Surgery 66.7 (2008): 1426-1438.

23. Lugmayr H., et al. "Morphologie und Inzidenz von Kieferhohlensepten. The morphology and incidence of maxillary sinus septa". Rofo 165.5 (1996): 452-454.

24. Kasabah S., et al. "Evaluation of the accuracy of panoramic radiograph in the definition of maxillary sinus septa". Acta Médica Portuguesa (Hradec Kralove). 45.4 (2002):173-175.

25. Kim MJ., et al. "Maxillary sinus septa: Prevalence, height, location, and morphology. A reformatted computed tomography scan analysis". Journal of Periodontology 77.5 (2006): 903-908.

26. González-Santana H., et al. "A study of the septa in the maxillary sinuses and the subantral alveolar processes in 30 patients". Journal of Oral Implantology 33.6 (2007):340-343.

27. Selcuk A., et al. "Variations of maxillary sinus and accompanying anatomical and pathological structures". Journal of Craniofacial Surgery 19.1 (2008):159-164.

28. Lee Wj., et al. "Analysis of location and prevalence of maxillary sinus septa". Journal of Periodontal and Implant Science 40.2 (2010): 56-60. 
29. Maestre-Ferrin L., et al. "Prevalence, location, and size of maxillary sinus septa: Panoramic radiograph versus computed tomography scan". Journal of Oral and Maxillofacial Surgery 69.2 (2011): 507-511.

30. Neugebauer J., et al. "Evaluation of maxillary sinus anatomy by cone-beam CT prior to sinus floor elevation". The International Journal of Oral and Maxillofacial Implants 25.2 (2010): 258-265.

31. Park YB., et al. "Analysis of the anatomy of the maxillary sinus septum using three-dimensional computed tomography". Journal of Oral and Maxillofacial Surgery 69.4 (2011):10701078.

32. Shen EC., et al. "Prevalence and location of maxillary sinus septa in the Taiwanese population and relationship to the absence of molars". Clinical Oral Implants Research 23.6 (2012): 741-745.

33. Li J., et al. "An anatomical study of maxillary sinus septum of Han population in Jiangsu region using cone-beam CT". Shanghai Kou Qiang Yi Xue 22.1 (2013): 52-57.

34. Orhan K., et al. "Cone beam CT evaluation of maxillary sinus septa prevalence, height, location and morphology in children and an adult population". Medical Principles and Practice 22.1 (2013): 47-53.

35. Nunes LS., et al. "Anatomical characteristics and dimensions of edentulous sites in the posterior maxillae of patients referred for implant therapy". International Journal of Periodontics and Restorative Dentistry 33.3 (2013): 337-345.

36. Dobele I., et al. "Radiographic assessment of findings in the maxillary sinus using cone-beam computed tomography". Stomatologija 15.4 (2013):119-122.

37. Jang SY., et al. "Comparative study of sinus septa between dentulous and dentulous patients by cone beam computed tomography". Implant Dentistry 23.4 (2014): 477-481.

38. Rancitelli D., et al. "Maxillary Sinus Septa and Anatomic Correlation with the Schneiderian Membrane". Journal of Craniofacial Surgery 26.4 (2015):1394-1398.

39. Gandhi KR., et al. "The incidence and morphology of maxillary sinus septa in dentate and edentulous maxillae: a cadaveric study with a brief review of the literature". Journal of the Korean Association of Oral and Maxillofacial Surgeons 41.1 (2015): 30-36.
40. Malec M., et al. "Maxillary sinus septa prevalence and morphology computed tomography based analysis". International Journal of Morphology 33 (2015): 144-148.

41. Sánchez-Pérez A., et al. "Characterization of the maxillary sinus using cone beam computed tomography. A retrospective radiographic study". Implant Dentistry 25.6 (2016): 762-769.

42. Qian L., et al. "Analysis of the morphology of maxillary sinus septa on reconstructed cone-beam computed tomography images". Journal of Oral and Maxillofacial Surgery74.4 (2016): 729-737.

43. Bornstein MM., et al. "An Analysis of frequency, morphology, and locations of maxillary sinus septa using cone beam computed tomography". The International Journal of Oral and Maxillofacial Implants 31.2 (2016): 280-287.

44. Sakhdari S., et al. "Determination of the prevalence, height, and location of the maxillary sinus septa using cone beam computed tomography". Implant Dentistry 25.3 (2016): 335340.

45. Toraman Alkurt M., et al. "Comparison of cone-beam computed tomography and panoramic radiographs in detecting maxillay sinus septa". Journal of Istanbul University Faculty of Dentistry 50.3 (2016): 8-14.

46. Tadinada A., et al. "Prevalence of bony, septa, antral pathology, and dimensions of the maxillary sinus from a sinus augmentation perspective: a retrospective cone-beam computed tomography study". Imaging Science in Dentistry 46.2 (2016):109115.

47. Keceli HG., et al. "Evaluation of single tooth loss to maxillary sinus and surrounding bone anatomy with cone-beam computed tomography: a multicenter study". Implant Dentistry 26.5 (2017): 690-699.

48. Lozano-Carrascal N., et al. "Radiological evaluation of maxillary sinus anatomy: a cross sectional study of 300 patients". Annals of Anatomy 214 (2017): 1-8.

49. Taleghani F., et al. "Prevalence, location, and size of maxillary sinus septa: computed tomography scan analysis". The Journal of Contemporary Dental Practice 8.1 (2017):11-15.

50. Talo Yildirim T., et al. "Evaluation of maxillary sinus septa: a retrospective clinical study with cone beam computerized tomography (СВCT)". European Review for Medical and Pharmacological Sciences 21.23 (2017): 5306-5314. 
51. Schriber M., et al. "Evaluating maxillary sinus septa using cone beam computed tomography: is there a difference in frequency and type between the dentate and edentulous posterior maxilla". The International Journal of Oral and Maxillofacial Implants 32.6 (2017):1324-1332.

52. Khalighi Sigaroudi A., et al. "Frequency of different maxillary sinus septal patterns found on cone-beam computed tomography and predicting the associated risk of sinus membrane perforation during sinus lifting". Imaging Science in Dentistry 47.4 (2017): 261-267.

53. Irinakis T., et al. "Complications during maxillary sinus augmentation associated with interfering septa: a new classification of septa". The Open Dentistry Journal 11 (2017): 140-150.

54. Genç T., et al. "Evaluation of anatomical structures and variations in the maxilla and the mandible before dental implant treatment". Dental and Medical Problems 55.3 (2018): 233240.

55. Hungerbühler A Rostetter C., et al. "Anatomical characteristics of maxillary sinus septa visualized by cone beam computed tomography". Int Journal of Oral and Maxillofacial Surgery 48.3 (2019): 382-387.

56. Dedeoğlu N and Altun O. "Evaluation of maxillary sinus anatomical variations and pathologies in elderly, young, posterior dentate and edentulous patient groups with cone beam computed tomography". Folia Morphologica (Warsz) (2019).

57. Şimşek Kaya G., et al. "The potential clinical relevance of anatomical structures and variations of the maxillary sinus for planned sinus floor elevation procedures: a retrospective cone beam computed tomography study". Clinical Implant Dentistry and Related Research 21.1 (2019): 114-121.

58. Zhang YQ., et al. "Morphologic analysis of maxillary sinus floor and its correlation to molar roots using cone beam computed tomography". Clinical Journal of Dental Research 22.1 (2019): 29-36.

59. Gülşen U., et al. "Horizontal maxillary sinus septa: An uncommon entity." International Journal of Surgery Case Reports 12 (2015): 67-70.

Volume 3 Issue 12 December 2019

(C) All rights are reserved by Yueh Ju Hsiao., et al. 